\title{
Implementation of evidence-based practice across medical, nursing, pharmacological and allied healthcare professionals: a questionnaire survey in nationwide hospital settings
}

Yi-Hao Weng ${ }^{1}$, Ken N Kuo ${ }^{2,3}$, Chun-Yuh Yang ${ }^{4}$, Heng-Lien Lo ${ }^{2,3}$, Chiehfeng Chen ${ }^{2,5,6,7}$ and Ya-Wen Chiu ${ }^{3,8,9^{*}}$

\begin{abstract}
Background: Implementation of evidence-based practice (EBP) is regarded as core competence to improve healthcare quality. In the current study, we investigated the EBP of six groups of professionals: physicians, nurses, pharmacists, physical therapists, technicians, and other allied healthcare personnel.

Methods: A structured questionnaire survey of regional hospitals throughout Taiwan was conducted by post in 2011. Questionnaires were mailed to all healthcare workers of 11 randomly selected hospitals. Linear and logistic regression models were used to examine predictors for implementing EBP.

Results: In total, 6,160 returned questionnaires, including 645 from physicians, 4,206 from nurses, 430 from pharmacists, 179 from physical therapists, 537 from technicians, and 163 from other allied healthcare professionals, were valid for the analysis. Physicians and pharmacists were more aware of EBP than were the other professional groups $(p<0.001)$. Positive attitudes toward and beliefs in EBP were significantly lower among nurses than in the other groups $(p<0.001)$. Physicians had more sufficient knowledge and skills of EBP than did the other professionals $(p<0.001)$; in addition, they implemented EBP for clinical decision-making more often and perceived fewer personal barriers to EBP $(p<0.001)$. Multivariate logistic regression analyses showed that EBP implementation was associated with the following characteristics of participants: EBP training, having a faculty position, academic degree, one's profession, and perceptions (beliefs, attitudes, knowledge, skills and barriers).

Conclusions: This study depicts various levels of EBP implementation among medical, nursing, pharmacological, and allied healthcare personnel. There were significant differences in their implementation of EBP. We observed that certain factors were associated with EBP implementation, including personal backgrounds and perceptions toward EBP. The data suggest that strategies for enhancing EBP implementation should differ for various groups of professionals.
\end{abstract}

\footnotetext{
* Correspondence: bettychiu@tmu.edu.tw

${ }^{3}$ Division of Preventive Medicine and Health Services Research, Institute of

Population Health Sciences, National Health Research Institutes, Miaoli,

Taiwan

${ }^{8}$ Master Program in Global Health and Development, College of Public

Health and Nutrition, Taipei Medical University, 250 Wu-Hsing Street, Taipei,

110, Taiwan

Full list of author information is available at the end of the article
} 


\section{Background}

Evidence-based practice (EBP) is clinical practice consistent with the current best evidence [1]. Implementation of EBP mainly involves four sequential steps [2]: first, framing a clear question based on a clinical problem; second, searching for relevant evidence in the literature; third, critically appraising the validity of contemporary research; and fourth, applying the findings to clinical decision-making. There are increasing examples illustrating that EBP can help healthcare professionals improve care quality [3-5]. Implementing EBP by all health professionals is thus needed [6-10].

Numerous studies have investigated the perceptions of EBP among a variety of healthcare-related professional groups [9-17]. Overall, most healthcare professionals hold positive attitudes toward EBP but lack sufficient knowledge and skills for implementation. A number of personal and organizational barriers impede EBP implementation [9,16-22]. To date, investigations of how health professionals implement EBP in clinical decisionmaking are still lacking $[23,24]$.

In regional hospitals of Taiwan, the majority of disease patterns are more complex than in primary-care settings. Health providers in regional hospitals devote most of their time to patient care. Therefore, it is essential to promote EBP among regional hospitals in order to improve the quality of healthcare. Since the beginning of 2007, the National Health Research Institutes (NHRI) has provided EBP-related information resources and promotional activities for healthcare professionals of regional hospitals in Taiwan [25]. Despite the NHRI's considerable ongoing efforts to encourage implementation of EBP, diffusion into regional hospitals is not yet widespread.

The backgrounds of physicians, nurses, pharmacists, and allied healthcare professionals naturally differ. Little research has focused on comparing the use of EBP among different healthcare professions. For EBP to be fully implemented, it is essential to clarify possible differences among professions. In this survey, we systematically assessed how EBP is perceived among all groups of healthcare professionals. This nationwide study allowed us to compare and contrast various levels of awareness, beliefs, attitudes, knowledge, skills, barriers, and implementation among various professions. The data provide critical evidence that can be used to guide strategies for improving the effectiveness of EBP dissemination.

\section{Materials/methods}

\section{Design}

A structured questionnaire was developed by the NHRI using questions based on our previously reported questionnaires $[16,26]$. The study was conducted during the four-month period of January to April 2011.

\section{Subjects}

Targets of this study were healthcare professionals working in regional hospitals in Taiwan. A regional hospital is defined as a secondary-care hospital accredited by Taiwan's Joint Commission of Hospital Accreditation. Cluster sampling was used to conduct the present study. Briefly, regional hospitals were divided into four clusters by location (northern, western, eastern and southern Taiwan), and a random sample of each cluster was selected. Since there were more hospitals in northern and western Taiwan, we selected more hospitals in those areas. Overall, we randomly enrolled 11 of the 65 regional hospitals in Taiwan, including 3 located in northern Taiwan, 4 in western Taiwan, and 2 each in eastern and southern Taiwan. The postal questionnaires were distributed to all healthcare professionals at the enrolled hospitals.

\section{Questionnaire}

The questionnaire included items for measuring the awareness of, beliefs in, attitudes toward, knowledge of, skills in, barriers to, and implementation of EBP. Questions were as follows.

1. Awareness: Have you heard of EBP (evidence-based practice) or related terms, such as EBM (evidencebased medicine), EBN (evidence-based nursing), or EBHC (evidence-based healthcare)?

2. Beliefs: Do you believe EBP is important for improving patient care quality?

3. Attitudes: Are you willing to support the promotion of EBP implementation?

4. Knowledge: Do you have sufficient knowledge to implement EBP principles?

5. Skills: Do you possess sufficient skills to implement EBP principles?

6. Implementation: In the past year, have you searched for relevant evidence in the literature to resolve your clinical questions, and then applied the findings to clinical decision-making after critical appraisal?

A. Have you changed your clinical decision-making through EBP implementation?

B. Have you added new clinical decision-making through EBP implementation?

C. Have you confirmed your clinical decision-making through EBP implementation?

Questions were rated using a Likert 5-point scale (strongly agree, agree, neutral, disagree, and strongly disagree) for attitudes, knowledge, skills and barriers.

Background characteristics included gender, age, teaching appointment, administrative position (defined as 
healthcare professionals who are in charge of administrative affairs), working experience, and academic degree. Academic level was divided into five categories: technical school degree; junior college (two-year university) degree; bachelor's degree (which requires seven years for medical school, six years for dental school, and four years for the other specialties); master's degree; and doctorate.

\section{Validity and reliability}

The content validity was examined by 10 experts with more than 15 years of clinical experience each [25]. The internal consistency of all indexes was estimated using Cronbach's alpha coefficient [25]. In this survey, a content validity index of 0.96 and Cronbach's coefficient alpha of 0.88 indicated sufficient validity and reliability of parameters in the questionnaire.

\section{Ethical considerations}

NHRI's Ethical Review Board approved the study protocol. The questionnaire was accompanied by an introductory letter stating the purpose of the study and promising confidentiality. Return of the completed questionnaire was considered consent to participate in the study. All questionnaires were anonymous.

\section{Statistical analyses}

The Likert 5-point scale was dichotomized for further analyses. A self-rating report of either 'strongly agree' or 'agree' was regarded as a favorable answer, while the other three ('neutral', 'disagree', and 'strongly disagree') were viewed as unfavorable answers. The statistical analyses were conducted using SPSS 12.0 for Windows (SPSS, Chicago, IL, USA). Categorical variables were analyzed using a Chi-square test. To explore predictors for the self-reported implementation of EBP, multiple logistic regression models were used. All odds ratios (ORs) and $95 \%$ confidence intervals (CIs) were adjusted for the other variables. Significance was defined as $\mathrm{p}<0.05$.

\section{Results}

\section{Awareness of EBP}

In total, 10,770 questionnaires were distributed to healthcare professionals of the enrolled hospitals, with 6,360 questionnaires returned (for a return rate of $59.1 \%)$. Of these, 6,160 valid questionnaires, 645 were from physicians, 4,206 from nurses, 430 from pharmacists, 179 from physical therapists (including occupational therapists), 537 from technicians (including diagnostic medical sonographers, medical technologists, and radiographers), and 163 from other allied healthcare professionals (including 5 from speech language therapists, 13 from psychological consultants, 50 from respiratory therapists, 67 from dietitians, and 28 from other groups of personnel).

Among the 6,160 respondents, 5,038 were aware of EBP or related terms (81.8\%). Awareness of EBP was associated with the following personal characteristics: gender $(\mathrm{p}<0.001)$, age $(\mathrm{p}<0.001)$, working experience $(\mathrm{p}<0.001)$, academic degree $(\mathrm{p}<0.001)$, a faculty position $(\mathrm{p}<0.001)$, a directorial position $(\mathrm{p}<0.001)$, and one's profession $(\mathrm{p}<0.001)$ (Table 1$)$. The greatest awareness of EBP was among physicians (95.2\%), and

Table 1 Awareness of evidence-based practice (EBP)

\begin{tabular}{|c|c|c|c|}
\hline & $\begin{array}{l}\text { All respondents } \\
\qquad N=6,160\end{array}$ & $\begin{array}{l}\text { Aware of EBP } \\
\mathrm{N}=5,038(\%)\end{array}$ & p-value \\
\hline Gender & & & $<0.001$ \\
\hline Male & 942 & 815 (86.5\%) & \\
\hline Female & 5,218 & 4,223 (80.9\%) & \\
\hline Age (years) & & & $<0.001$ \\
\hline $20 \sim 30$ & 2,760 & 2,083 (75.5\%) & \\
\hline $31 \sim 40$ & 2,571 & 2,211 (86.0\%) & \\
\hline $41 \sim 50$ & 664 & 599 (90.2\%) & \\
\hline$>50$ & 165 & 145 (87.9\%) & \\
\hline
\end{tabular}

Working experience

$<0.001$

(years)

$\begin{array}{lll}<5 & 2,108 & 1,611(76.4 \%) \\ 5 \sim 10 & 2,384 & 1,934(81.1 \%) \\ >10 & 1,668 & 1,493(89.5 \%)\end{array}$

Academic level

Technical school

1,846

$1,384(75.0 \%)$

Junior college

1,809

$1,464(80.9 \%)$

Bachelor's*

2,062

1,773 (86.0\%)

Master's

401

377 (94.0\%)

Doctorate

42

$40(95.2 \%)$

Faculty position (\%)

$<0.001$

Yes

1,219

$1,129(92.6 \%)$

No

4,941

3,909 (79.1\%)

Director (\%)

With

620

$<0.001$

Without

5,540

597 (96.3\%)

$4,441(80.2 \%)$

Profession

$\begin{array}{lcc}\text { Physician } & 645 & 614(95.2 \%) \\ \text { Nurse } & 4,206 & 3,354(79.7 \%) \\ \text { Pharmacist } & 430 & 401(93.3 \%) \\ \text { Physical therapist } & 179 & 149(83.2 \%) \\ \text { Technician } & 537 & 382(71.1 \%) \\ \text { Other } & 163 & 138(84.7 \%)\end{array}$

$<0.001$

The bachelor's curriculum is seven years for medical school, six years for dental school, and four years for the other specialties. 
technicians (95.2\%), followed by pharmacists (93.3\%), other allied professions (84.7\%), physical therapists (83.2\%), nurses (79.7\%).

Beliefs in, attitudes toward, knowledge of, and skills of participants

Among the 5,038 participants who were aware of EBP, 3,604 healthcare professionals reported believing that EBP is important for improving patient care quality (71.5\%), and 3,015 stated that they were willing to support implementation of EBP (59.8\%) (Figure 1). However, their self-reported knowledge of (28.7\%) and skills in $(16.8 \%)$ implementing EBP principles were relatively insufficient. There were significant discrepancies in beliefs, attitudes, knowledge and skills among the six groups of professions $(\mathrm{p}<0.001)$. Physicians and pharmacists were more likely to hold positive beliefs in and attitudes toward EBP $(\mathrm{p}<0.001)$. Furthermore, physicians tended to have more sufficient knowledge of and skills in EBP than did the other professional groups $(\mathrm{p}<0.001)$.

\section{Implementation of EBP}

Among the 5,038 participants who were aware of EBP, 2,111 respondents reported having implemented EBP for clinical decision-making in the previous year (41.9\%). There were significant differences in the frequency of EBP implementation among the six groups of professionals $(\mathrm{p}<0.001)$ (Figure 2$)$. Physicians reported implementing EBP the most $(\mathrm{p}<0.001)$. In contrast, nurses, pharmacists, and technicians reported implementing EBP the least. Overall, 166 reported implementing EBP daily (7.9\%), 266 weekly (12.6\%), 568 monthly (26.9\%), 480 quarterly (22.7\%), and 631 yearly (29.9\%).

The behaviors reported for EBP implementation involved changes in $(57.0 \%)$, additions to $(58.4 \%)$, and reaffirmations of (56.8\%) decision-making (Figure 3). Physicians and physical therapists more often implemented

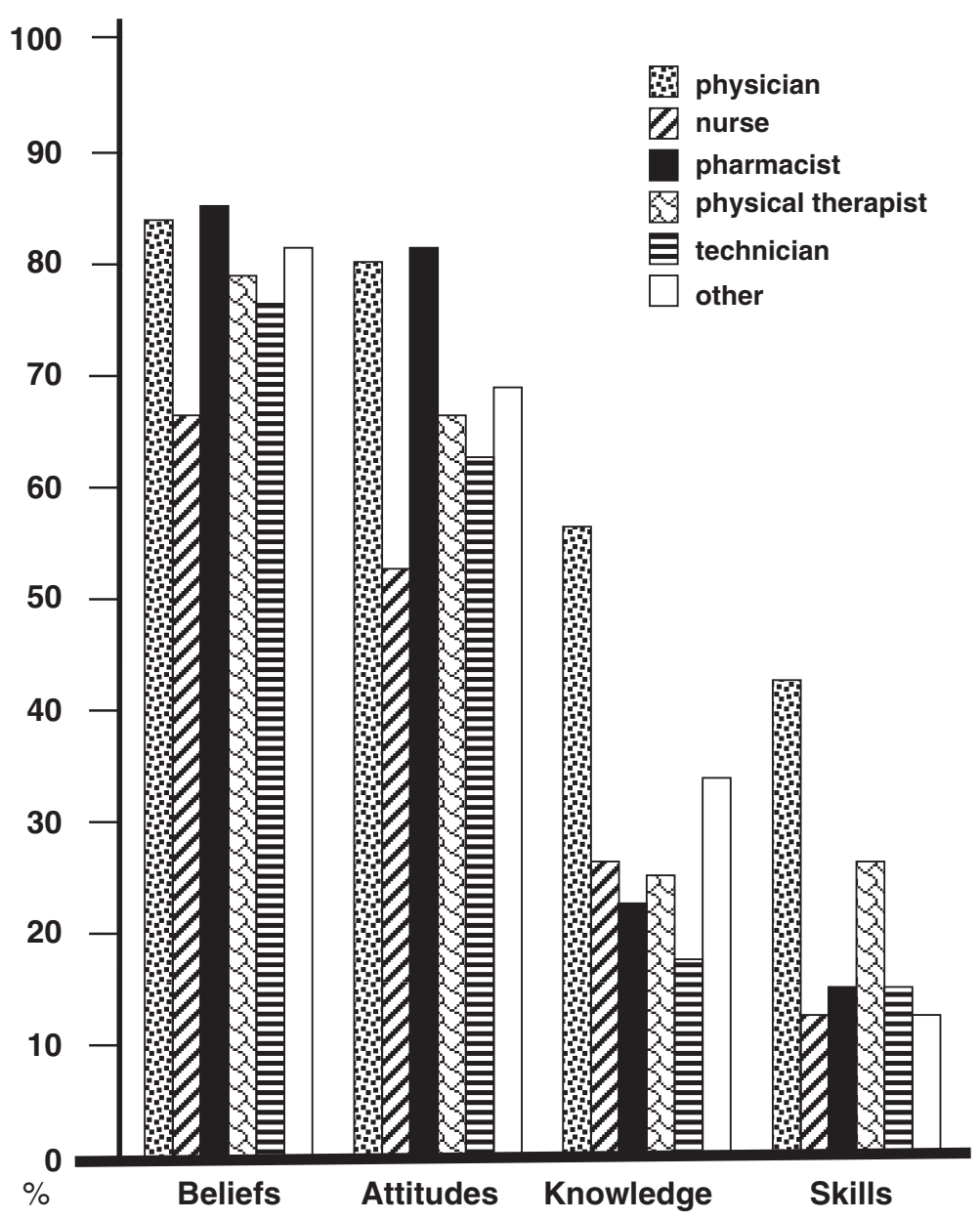

Figure 1 Four evidence-based practice (EBP) characteristics among 6 groups of healthcare professionals. Beliefs: EBP is important to improve patient care quality. Attitudes: I am willing to support the promotion of EBP implementation. Knowledge: I have sufficient knowledge to implement EBP principles. Skills: I possess sufficient skills to implement EBP principles. 


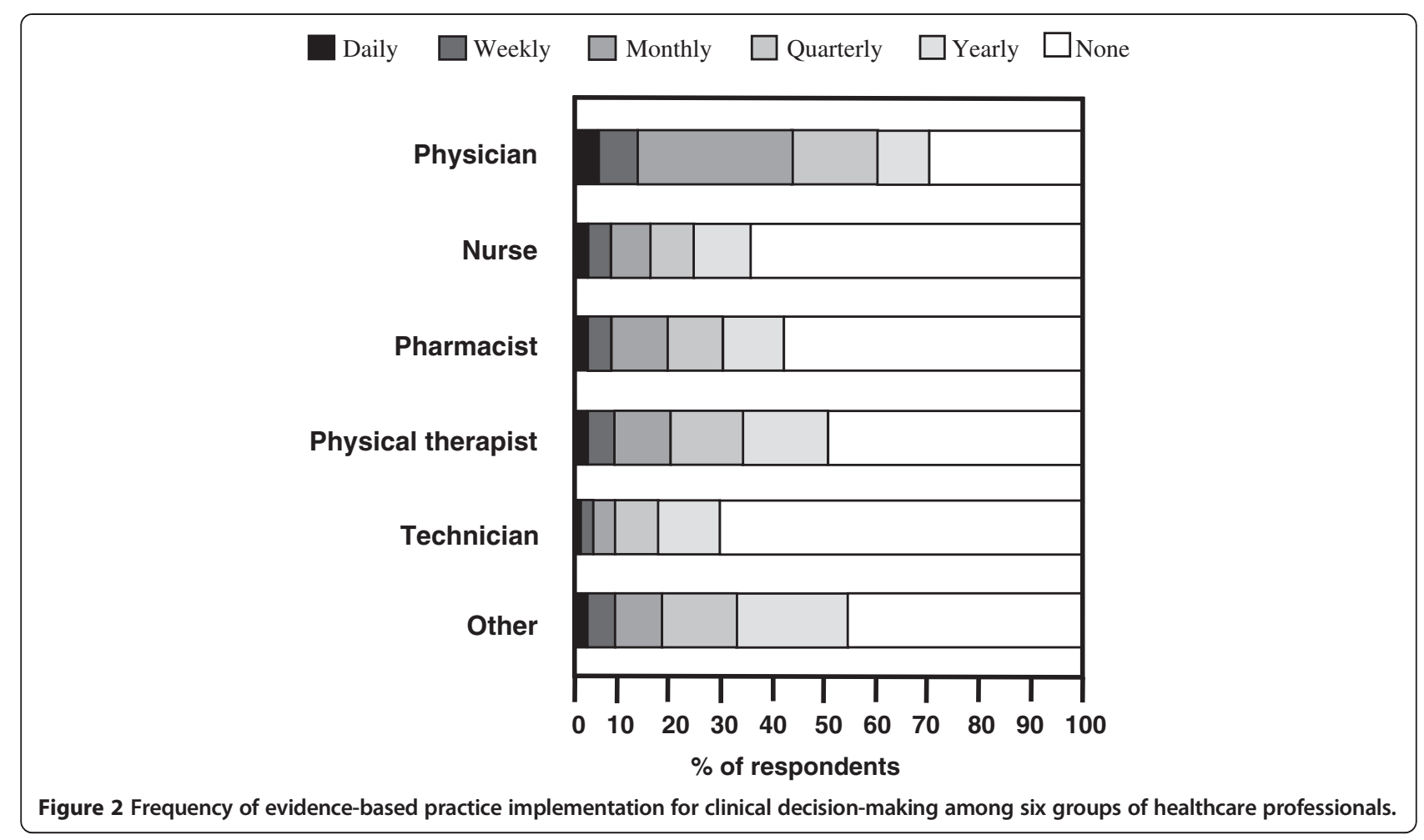

EBP to change, add and reaffirm their decision-making, whereas technicians implemented EBP the least $(\mathrm{p}<0.001)$. However, there were no statistically significant differences in these three behaviors within any professional group.

\section{Barriers to and training in EBP}

Barriers to implementing EBP were categorized into personal and environmental factors. Table 2 summarizes the barriers of personal and environmental factors. Barriers in relation to the organizations and colleagues of

I have changed my clinical decision-makingthrough EBP implementation

$\square$ I have newly added my clinical decision-makingthrough EBP implementation

$\square$ I have reassured my clinical decision-makingthrough EBP implementation

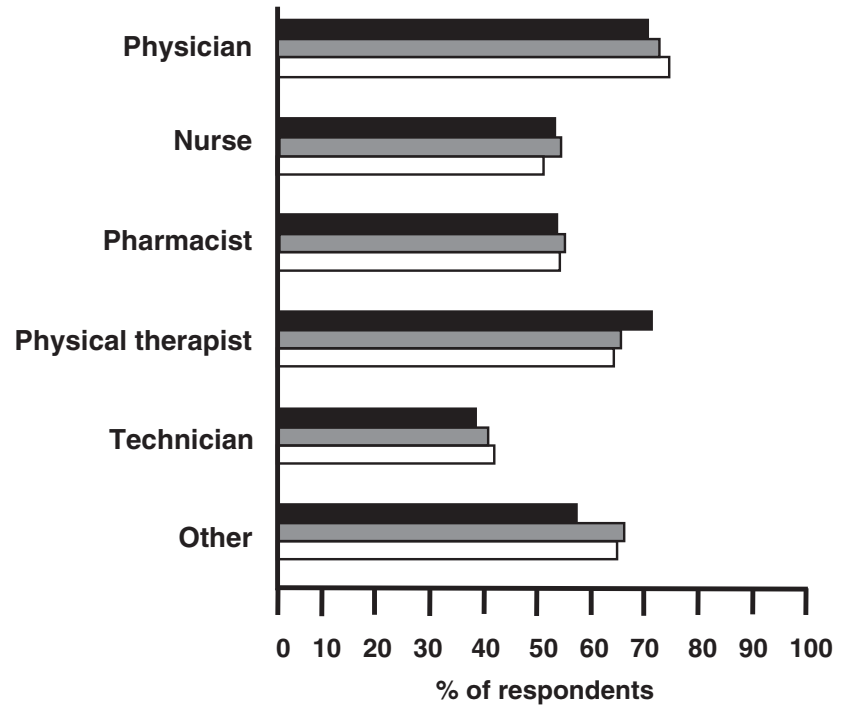

Figure 3 Behavior of evidence-based practice (EBP) implementation for clinical decision-making among six groups of healthcare professionals. 
Table 2 Barriers to evidence-based practice (EBP) implementation

\begin{tabular}{|c|c|c|c|c|c|c|c|c|}
\hline \multirow[t]{2}{*}{ Lack of - N (\%) } & All & Physician & Nurse & Pharmacist & $\begin{array}{l}\text { Physical } \\
\text { therapist }\end{array}$ & Technician & Other & \multirow[t]{2}{*}{$p$ - value } \\
\hline & $\mathrm{N}=5,038$ & $\mathrm{~N}=614$ & $\mathrm{~N}=3,354$ & $\mathrm{~N}=401$ & $N=149$ & $\mathrm{~N}=382$ & $\mathrm{~N}=138$ & \\
\hline \multicolumn{9}{|l|}{ Personal } \\
\hline Time, due to a heavy clinical load & $2,714(53.9)$ & $253(41.2)$ & $1,859(55.4)$ & $233(58.1)$ & $90(60.4)$ & $207(54.2)$ & $72(52.2)$ & $<0.001$ \\
\hline Basic knowledge & $2,461(48.8)$ & $175(28.5)$ & $1,798(53.6)$ & $186(46.4)$ & $65(43.6)$ & $183(47.9)$ & $54(39.1)$ & $<0.001$ \\
\hline Skills in critical appraisal & $2,437(48.4)$ & $227(37.0)$ & $1,692(50.4)$ & $235(58.6)$ & $58(38.9)$ & $162(42.4)$ & $63(45.7)$ & $<0.001$ \\
\hline Skills in literature searching & $2,150(42.7)$ & $178(29.0)$ & $1,519(45.3)$ & $193(48.1)$ & $54(36.2)$ & $150(39.3)$ & $56(40.6)$ & $<0.001$ \\
\hline Clinical incorporation & $1,543(30.6)$ & $132(21.5)$ & $1,111(33.1)$ & $124(30.9)$ & $32(21.5)$ & $106(27.7)$ & $38(27.5)$ & $<0.001$ \\
\hline \multicolumn{9}{|l|}{ Environmental } \\
\hline Convenient application kits & $2,905(57.7)$ & $312(50.8)$ & $1,916(57.1)$ & $256(63.8)$ & $97(65.1)$ & $244(63.9)$ & $80(58.0)$ & $<0.001$ \\
\hline Library resources in Chinese & $2,646(52.5)$ & $328(53.4)$ & $1,690(50.4)$ & $243(60.6)$ & $91(61.1)$ & $209(54.7)$ & $85(61.6)$ & $<0.001$ \\
\hline Capable designated personnel & $2,330(46.2)$ & $202(32.9)$ & $1,619(48.3)$ & $191(47.6)$ & $69(46.3)$ & $189(49.5)$ & $60(43.5)$ & $<0.001$ \\
\hline Space for access to EBP resources & $2,243(44.5)$ & $234(38.1)$ & $1,476(44.0)$ & $199(49.6)$ & $93(62.4)$ & $190(49.7)$ & $51(37.0)$ & $<0.001$ \\
\hline Library resources & $1,956(38.8)$ & $177(28.8)$ & $1,373(40.9)$ & $140(34.9)$ & $53(35.6)$ & $157(41.1)$ & $56(40.6)$ & $<0.001$ \\
\hline An EBP-supportive organizational climate & $1,122(22.3)$ & $107(17.4)$ & $808(24.1)$ & $81(20.2)$ & $28(18.8)$ & $71(18.6)$ & $27(19.6)$ & 0.001 \\
\hline Support from superiors & $779(15.5)$ & $76(12.4)$ & $584(17.4)$ & $44(11.0)$ & $18(12.1)$ & $40(10.5)$ & $17(12.3)$ & $<0.001$ \\
\hline
\end{tabular}

the respondents were regarded as environmental factors. The most common barrier was a lack of convenient kits (such as personal digital assistants and brochures) (57.7\%), followed by time constraints (53.9\%), a lack of library resources in Chinese (52.5\%), deficient basic knowledge (48.8\%), deficient skills in critical appraisal (48.4\%), an insufficient number of capable designated personnel (46.2\%), limited space for access to EBP resources (44.5\%), deficient skills in literature searching (42.7\%), insufficient library resources $(38.8 \%)$, a lack of incorporation with clinical practice (30.6\%), a lack of an EBP-supportive organizational climate (22.3\%), and a lack of support from superiors (15.5\%). There were significant differences in both personal and environmental barriers among the six groups of professionals. Physicians perceived fewer personal and environmental barriers than did those in other professional groups $(\mathrm{p}<0.001)$.

In addition, 1,528 health professionals (30.3\%) reported having participated in a training course for EBP implementation and/or use. Physicians and pharmacists reported more often participating in a training course for EBP than did the other professionals $(\mathrm{p}<0.001)$ (data not shown).

\section{Factors associated with implementation of EBP}

The univariate analyses showed significant correlations of self-reported EBP implementation with the following 13 characteristics: beliefs, attitudes, knowledge, skills, barriers, training, gender, a faculty position, a director position, academic degree, working experience, age, and one's profession. Multivariate logistic regression analyses
(Table 3) demonstrated that EBP implementation was more common in healthcare personnel with positive beliefs $(\mathrm{OR}=1.49,95 \% \mathrm{CI}=1.23$ to approx. 1.79$)$, favorable attitudes $(\mathrm{OR}=1.25,95 \% \mathrm{CI}=1.05$ to approx. 1.48), sufficient knowledge $(\mathrm{OR}=1.66,95 \% \mathrm{CI}=1.38$ to approx. 1.99), sufficient skills $(\mathrm{OR}=1.35,95 \% \quad \mathrm{CI}=1.15$ to approx. 1.59), participation in EBP training $(\mathrm{OR}=1.91$, $95 \% \mathrm{CI}=1.62$ to approx. 2.26), and a faculty position $(\mathrm{OR}=1.49,95 \% \mathrm{CI}=1.25$ to approx. 1.78). Healthcare personnel with a bachelor's $(\mathrm{OR}=1.24,95 \% \mathrm{CI}=1.02$ to approx. 1.50) or master's or doctoral degree $(\mathrm{OR}=1.45$, $95 \% \mathrm{CI}=1.06$ to approx. 1.98$)$ were more likely to implement EBP than those who had graduated from a technical school. In addition, physicians $(\mathrm{OR}=1.93,95 \%$ $\mathrm{CI}=1.39$ to approx. 2.68) and other allied healthcare professionals (including speech language therapists, psychological consultants, respiratory therapists, and dietitians $)(\mathrm{OR}=1.53,95 \% \mathrm{CI}=1.01$ to approx. 2.31) implemented EBP more frequently than nurses, whereas technicians were less likely to implement EBP than nurses $(\mathrm{OR}=0.57,95 \% \mathrm{CI}=0.44$ to approx. 0.76). In contrast, EBP implementation was less common among healthcare professionals who reported a lack of basic knowledge $(\mathrm{OR}=0.82,95 \% \mathrm{CI}=0.69$ to approx. 0.96) and skills in literature searching $(\mathrm{OR}=0.78,95 \% \mathrm{CI}=$ 0.64 to approx. 0.95 ) as barriers to EBP use.

\section{Discussion}

In this study, we describe perceptions of EBP implementation among medical, nursing, pharmacological, and allied healthcare professionals in Taiwan. Our results demonstrate that a majority of healthcare personnel 
Table 3 Factors associated with the implementation of evidence-based practice (EBP), by a multivariate logistic regression analysis

\begin{tabular}{|c|c|c|c|c|c|}
\hline EBP implementation & $\begin{array}{c}\text { Yes } \\
\mathrm{N}=2111\end{array}$ & $\begin{array}{c}\text { No } \\
N=2927\end{array}$ & OR & $95 \% \mathrm{Cl}$ & p-value \\
\hline Beliefs & $1,696(80.3)$ & $1,908(65.2)$ & 1.485 & $1.230 \sim 1.792$ & $<0.001$ \\
\hline Attitudes & $1,476(69.9)$ & $1,539(52.6)$ & 1.248 & $1.052 \sim 1.479$ & 0.011 \\
\hline Knowledge & $788(37.3)$ & $656(22.4)$ & 1.655 & $1.377 \sim 1.989$ & $<0.001$ \\
\hline Skills & $536(25.4)$ & $312(10.7)$ & 1.354 & $1.153 \sim 1.591$ & $<0.001$ \\
\hline Training & $981(56.5)$ & $547(18.7)$ & 1.914 & $1.618 \sim 2.264$ & $<0.001$ \\
\hline \multicolumn{6}{|l|}{ Barriers - lack of } \\
\hline Time & 710 (33.6) & $1,246(42.6)$ & 1.042 & $0.886 \sim 1.225$ & 0.621 \\
\hline Basic knowledge & $710(33.6)$ & $1,246(42.6)$ & 0.816 & $0.694 \sim 0.959$ & 0.014 \\
\hline Skills in critical appraisal & 710 (33.6) & $1,246(42.6)$ & 1.013 & $0.837 \sim 1.226$ & 0.895 \\
\hline Skills in literature searching & $905(42.9)$ & $1,532(52.3)$ & 0.777 & $0.640 \sim 0.944$ & 0.011 \\
\hline Clinical incorporation & $1,188(56.3)$ & $1,717(58.7)$ & 0.844 & $0.708 \sim 1.006$ & 0.059 \\
\hline Convenient application kits & $1,045(49.5)$ & $1,669(57.0)$ & 1.132 & $0.950 \sim 1.349$ & 0.167 \\
\hline Capable designated personnel & $748(35.4)$ & $1,402(47.9)$ & 0.978 & $0.824 \sim 1.162$ & 0.804 \\
\hline Space for access to EBP resources & $858(40.6)$ & $16.3(54.8)$ & 0.990 & $0.830 \sim 1.182$ & 0.914 \\
\hline Library resources & $899(42.6)$ & $1,431(48.9)$ & 0.849 & $0.716 \sim 1.007$ & 0.060 \\
\hline Organizational climate & $519(24.6)$ & $1,024(35.0)$ & 1.043 & $0.832 \sim 1.307$ & 0.716 \\
\hline Support from superiors & $873(41.4)$ & $1,370(46.8)$ & 0.826 & $0.635 \sim 1.075$ & 0.156 \\
\hline \multicolumn{6}{|l|}{ Demographic } \\
\hline Male & $495(23.4)$ & $320(10.9)$ & 1.124 & $0.868 \sim 1.454$ & 0.375 \\
\hline Director & $358(17.0)$ & $239(8.2)$ & 1.237 & $0.975 \sim 1.569$ & 0.080 \\
\hline Faculty & $633(30.0)$ & $496(16.9)$ & 1.490 & $1.247 \sim 1.780$ & $<0.001$ \\
\hline \multicolumn{6}{|l|}{ Profession } \\
\hline Physician & $436(20.7)$ & $178(6.1)$ & 1.932 & $1.394 \sim 2.678$ & $<0.001$ \\
\hline Pharmacist & $169(8.0)$ & $232(7.9)$ & 0.801 & $0.610 \sim 1.051$ & 0.110 \\
\hline Physical therapist & $78(3.7)$ & $71(2.5)$ & 1.137 & $0.764 \sim 1.692$ & 0.526 \\
\hline Technician & $122(5.8)$ & $260(8.8)$ & 0.574 & $0.436 \sim 0.755$ & $<0.001$ \\
\hline Other allied & $75(3.6)$ & $63(2.2)$ & 1.527 & $1.009 \sim 2.310$ & 0.045 \\
\hline Nurse & $1,231(58.2)$ & $2,123(72.5)$ & & reference & \\
\hline \multicolumn{6}{|l|}{ Working experience (years) } \\
\hline$<5$ & $630(29.8)$ & $981(33.5)$ & 0.937 & $0.727 \sim 1.208$ & 0.617 \\
\hline $5 \sim 10$ & $782(33.0)$ & $1,152(39.4)$ & 0.928 & $0.762 \sim 1.130$ & 0.457 \\
\hline$>10$ & $699(33.2)$ & $794(27.1)$ & & reference & \\
\hline \multicolumn{6}{|l|}{ Academic level } \\
\hline Master's or doctorate & $275(13.0)$ & $142(4.8)$ & 1.445 & $1.056 \sim 1.978$ & 0.022 \\
\hline Bachelor's & $861(40.8)$ & $912(31.2)$ & 1.240 & $1.024 \sim 1.501$ & 0.027 \\
\hline Junior college & $521(24.7)$ & $943(32.2)$ & 1.078 & $0.904 \sim 1.285$ & 0.403 \\
\hline Technical school & $454(21.5)$ & $930(31.8)$ & & reference & \\
\hline \multicolumn{6}{|l|}{ Age (years) } \\
\hline $20 \sim 30$ & $775(36.7)$ & $1,308(44.7)$ & 1.331 & $0.985 \sim 1.799$ & 0.063 \\
\hline $31 \sim 40$ & $974(46.1)$ & $1,237(42.3)$ & 1.214 & $0.961 \sim 1.534$ & 0.104 \\
\hline$>40$ & $362(17.2)$ & $382(13.0)$ & & reference & \\
\hline
\end{tabular}


have favorable beliefs in and attitudes toward EBP. However, their knowledge of and skills in EBP are limited. These findings are in accordance with previous studies of a variety of professional healthcare groups [10,13-17,27-29]. In addition, our data showed that EBP has not yet widely diffused into all groups of healthcare professionals in Taiwan. The results of this study have clinical implications for healthcare organization leaders and policymakers who wish to disseminate and implement EBP more broadly.

There were important differences related to EBP across the professional groups. Discrepancies among the groups in awareness of, beliefs in, attitudes toward, knowledge of, skills in, barriers to, and behavior regarding EBP were wide. First, physicians and pharmacists were the most aware of EBP. This is likely due to a long history of exposure to and efforts to influence the use of EBP [16]. In contrast, technicians were the least aware of EBP. A similar report from Upton et al. showed that technicians have poor awareness of EBP [12]. In addition, our results identified a number of factors related to an awareness of EBP, such as age and gender. Nevertheless, these factors were exclusively associated with the demographic characteristics of the professions [30]. Second, physicians and pharmacists were more likely to recognize the value of EBP. These findings are generally consistent with results of previous studies [13,17,27]. Burkiewicz et al. reported positive views toward EBP in as many as $90 \%$ of pharmacists [13]. Furthermore, nurses held the most unfavorable beliefs and attitudes toward EBP; this may have been due to unfamiliarity with EBP [16]. Third, physicians had more sufficient knowledge and skills than the other groups. This may be because EBP is a part of the initial educational training for physicians. Similar studies supported our findings in showing that physicians possess greater capability to implement EBP than nurses and allied healthcare personnel $[16,17]$. Fourth, physicians reported implementing EBP the most, whereas nurses and technicians implemented EBP the least. It is possible that clinical roles of physicians, nurses, and technicians are divergent. Physicians need to find evidence based on the best quality and make clinical decisions for the most effective healthcare. In contrast, hospital-based nurses and technicians may rely more on clear directions rather and may have less discretion in medical decision-making.

In addition to examining EBP-related differences among those in different professions, our study highlighted several factors in relation to implementing EBP. First, positive perceptions and high self-efficacy appear to be primary influences on implementation. Other studies similarly indicated that EBP users have morefavorable attitudes toward, knowledge of, and skills in EBP than non-users [23,31,32]. Second, a faculty position, educational training, and academic degree are important factors affecting implementation of EBP. Our previous study identified being a faculty member as a significant position from which to search for evidence-based information [33]. Furthermore, our data showed that healthcare professionals with a high academic degree or with educational training more often implemented EBP than those without either of these. Third, deficient knowledge and skills were negative predictors of EBP implementation. Taken together, our data support the importance of providing advanced education and training courses to facilitate the implementation of EBP. Our findings concur with other available literature showing that effective teaching programs can increase behaviors that support EBP implementation [2,34].

In terms of barriers to implementing EBP, the results of this study are similar to findings in other countries $[15,20,35,36]$. A lack of time is the most commonly reported personal barrier for healthcare professionals around the world [14,37-39]. In addition, insufficient knowledge and skills are significant barriers to EBP $[37,40]$. Nevertheless, our data indicated that a number of barriers were unique to organizational settings. In particular, our survey found that language barriers were a significant barrier to our participants. This is supported by our previous survey showing that nurses preferred evidence-based resources to be available in Chinese [26].

There are some limitations to this study. First, this was a self-administered survey, not an audit of actual practice; the results might not reflect the realities of practice under routine clinical care [22]. Second, inaccuracies may have occurred in the questionnaire survey; however, there is no other reliable method for collecting such data on a nationwide basis. Third, the return rate of this questionnaire survey was 59.1\%; however, we believe our respondents are a representative sample because their backgrounds were similar to those in our previous surveys $[16,26,30]$. In spite of these limitations, our survey presents several potentially useful findings. Our study differs from previous studies examining informationsearching patterns in that we evaluated self-reported EBP-related behaviors in the context of clinical decisionmaking, which is a vital component in implementing research evidence into clinical practice [22]. To our knowledge, this study is the first survey to systematically assess EBP implementation across physicians, nurses, pharmacists, and allied healthcare professionals.

\section{Conclusions}

The significance of the present study stems from its focus on evaluating implementation of EBP in daily clinical practice. We used a large-scale questionnaire survey to compare various levels of perceptions toward EBP 
among all groups of healthcare professionals. Our data showed that healthcare professionals more often integrate evidence into clinical decision-making when the following characteristics are present: positive perceptions toward EBP, high self-efficacy to perform EBP, educational training for EBP, and having a faculty position and a high academic degree. To the extent possible, education and training that support these factors may help to increase positive beliefs and attitudes regarding EBP, and ultimately, EBP use in practice.

\section{Competing interests}

The authors declare that they have no competing interests.

\section{Authors' contributions \\ YHW, KNK, and YWC conceived and developed the study and drafted the manuscript. KNK and YWC were responsible for organizing the team and obtaining funding. CYY, HLL, and CC assisted with coordinating the study and drafting the manuscript. All authors read and approved the final manuscript.}

\section{Acknowledgements}

The authors are grateful to the participants who gave of their time to fill out the questionnaire for this study. They thank Ms. Ya-Hui Shih for her dedicated work on collecting research data. This work was supported by research grants from the National Health Research Institutes (PH-099-SP02), National Science Council (NSC 102-2511-S-038-005), Taipei Medical University (TMU 101-AE1-B68), and Chang Gung Memorial Hospital (CMRPG1B0131).

\section{Author details}

'Department of Pediatrics, Chang Gung Memorial Hospital, Chang Gung University College of Medicine, Taipei, Taiwan. ${ }^{2}$ Center for Evidence-Based Medicine, Taipei Medical University, Taipei, Taiwan. ${ }^{3}$ Division of Preventive Medicine and Health Services Research, Institute of Population Health Sciences, National Health Research Institutes, Miaoli, Taiwan. ${ }^{4}$ Department of Public Health, Kaohsiung Medical University, Kaohsiung, Taiwan. ${ }^{5}$ Division of Plastic Surgery, Department of Surgery, Wan Fang Hospital, Taipei Medical University, Taipei, Taiwan. ${ }^{6}$ Evidence-Based Medicine Center, Wan Fang Hospital, Taipei Medical University, Taipei, Taiwan. ${ }^{7}$ Department of Public Health, School of Medicine, College of Medicine, Taipei Medical University, Taipei, Taiwan. ${ }^{8}$ Master Program in Global Health and Development, College of Public Health and Nutrition, Taipei Medical University, 250 Wu-Hsing Street, Taipei, 110, Taiwan. ${ }^{9}$ Health Policy and Care Research Center, Taipei Medical University, Taipei, Taiwan.

Received: 5 February 2013 Accepted: 17 September 2013 Published: 24 September 2013

\section{References}

1. Sackett DL, Rosenberg WM, Gray JA, Haynes RB, Richardson WS: Evidence based medicine: what it is and what it isn't. BMJ 1996, 312:71-72.

2. Thomas A, Saroyan A, Dauphinee WD: Evidence-based practice: a review of theoretical assumptions and effectiveness of teaching and assessment interventions in health professions. Adv Health Sci Educ Theory Pract 2011, 16:253-276

3. Glasziou P, Ogrinc G, Goodman S: Can evidence-based medicine and clinical quality improvement learn from each other? BMJ Qual Saf 2011, 20:113-17.

4. Riba AL: Evidence-based performance and quality improvement in the acute cardiac care setting. Crit Care Clin 2008, 24:201-229.

5. Mulvaney SA, Bickman L, Giuse NB, Lambert EW, Sathe NA, Jerome RN: A randomized effectiveness trial of a clinical informatics consult service: impact on evidence-based decision-making and knowledge implementation. J Am Med Inform Assoc 2008, 15:203-211.

6. Grol R: Successes and failures in the implementation of evidence-based guidelines for clinical practice. Med Care 2001, 39:||46-54.
7. Waters D, Crisp J, Rychetnik L, Barratt A: The Australian experience of nurses' preparedness for evidence-based practice. J Nurs Manag 2009, 17:510-518.

8. Pravikoff DS, Tanner AB, Pierce ST: Readiness of U.S. nurses for evidencebased practice. Am J Nurs 2005, 105:40-51.

9. Knops AM, Vermeulen H, Legemate DA, Ubbink DT: Attitudes, awareness, and barriers regarding evidence-based surgery among surgeons and surgical nurses. World J Surg 2009, 33:1348-1355.

10. Heiwe S, Kajermo KN, Tyni-Lenne R, Guidetti S, Samuelsson M, Andersson IL, Wengstrom Y: Evidence-based practice: attitudes, knowledge and behaviour among allied health care professionals. Int I Qual Health Care 2011, 23:198-209.

11. McEvoy MP, Williams MT, Olds TS: Evidence based practice profiles: differences among allied health professions. BMC Med Educ 2010, 10:69.

12. Upton D, Upton P: Knowledge and use of evidence-based practice by allied health and health science professionals in the United Kingdom. J Allied Health 2006, 35:127-133.

13. Burkiewicz JS, Zgarrick DP: Evidence-based practice by pharmacists: utilization and barriers. Ann Pharmacother 2005, 39:1214-1219.

14. O'Donnell CA: Attitudes and knowledge of primary care professionals towards evidence-based practice: a postal survey. J Eval Clin Pract 2004, 10:197-205

15. Jette DU, Bacon K, Batty C, Carlson M, Ferland A, Hemingway RD, Hill JC, Ogilvie L, Volk D: Evidence-based practice: beliefs, attitudes, knowledge, and behaviors of physical therapists. Phys Ther 2003, 83:786-805.

16. Chiu YW, Weng YH, Lo HL, Hsu CC, Shih YH, Kuo KN: Comparison of evidence-based practice between physicians and nurses: a national survey of regional hospitals in Taiwan. J Contin Educ Health Prof 2010, 30:132-138.

17. Lai NM, Teng CL, Lee ML: The place and barriers of evidence based practice: knowledge and perceptions of medical, nursing and allied health practitioners in malaysia. BMC Res Notes 2010, 3:279.

18. Aarons GA, Sawitzky AC: Organizational Culture and Climate and Mental Health Provider Attitudes Toward Evidence-Based Practice. Psychol Serv 2006, 3:61-72.

19. Atkinson M, Turkel M, Cashy J: Overcoming barriers to research in a magnet community hospital. J Nurs Care Qual 2008, 23:362-368.

20. Bostrom AM, Kajermo KN, Nordstrom G, Wallin L: Barriers to research utilization and research use among registered nurses working in the care of older people: Does the BARRIERS Scale discriminate between research users and non-research users on perceptions of barriers? Implement Sci 2008, 3:24.

21. Caspi O, McKnight P, Kruse L, Cunningham V, Figueredo AJ, Sechrest L Evidence-based medicine: discrepancy between perceived competence and actual performance among graduating medical students. Med Teach 2006, 28:318-325.

22. Thompson C, McCaughan D, Cullum N, Sheldon T, Raynor P: Barriers to evidence-based practice in primary care nursing-why viewing decisionmaking as context is helpful. J Adv Nurs 2005, 52:432-444.

23. McAlister FA, Graham I, Karr GW, Laupacis A: Evidence-based medicine and the practicing clinician. J Gen Intern Med 1999, 14:236-242.

24. Squires JE, Hutchinson AM, Bostrom AM, O'Rourke HM, Cobban SJ, Estabrooks CA: To what extent do nurses use research in clinical practice? A systematic review. Implement Sci 2011, 6:21.

25. Chiu YW, Weng YH, Lo HL, Hsu CC, Shih YH, Kuo KN: Impact of a nationwide outreach program on the diffusion of evidence-based practice in Taiwan. Int J Qual Health Care 2010, 22:430-436.

26. Chiu YW, Weng YH, Lo HL, Shih YH, Hsu CC, Kuo KN: Comparison of accessing online databases between physicians and nurses in Taiwan. Inform Health Soc Care 2012, 37:230-241.

27. Peterson GM, Jackson SL, Fitzmaurice KD, Gee PR: Attitudes of Australian pharmacists towards practice-based research. J Clin Pharm Ther 2009, 34:397-405

28. Hadley JA, Wall D, Khan KS: Learning needs analysis to guide teaching evidence-based medicine: knowledge and beliefs amongst trainees from various specialities. BMC Med Educ 2007, 7:11.

29. Sherriff KL, Wallis M, Chaboyer W: Nurses' attitudes to and perceptions of knowledge and skills regarding evidence-based practice. Int J Nurs Pract 2007, 13:363-369.

30. Weng $Y H$, Kuo KN, Yang CY, Lo HL, Shih YH, Chiu YW: Informationsearching behaviors of main and allied health professionals: a 
nationwide survey in Taiwan. J Eval Clin Pract 2012, doi:10.1111/ j.1365-2753.2012.01871.x. [Epub ahead of print].

31. Skoglund I, Segesten K, Bjorkelund C: GPs' thoughts on prescribing medication and evidence-based knowledge: the benefit aspect is a strong motivator. A descriptive focus group study. Scand J Prim Health Care 2007, 25:98-104.

32. Squires JE, Estabrooks CA, Gustavsson P, Wallin L: Individual determinants of research utilization by nurses: a systematic review update. Implement Sci 2011, 6:1.

33. Chiu YW, Weng YH, Lo HL, Ting HW, Hsu CC, Shih YH, Kuo KN: Physicians' characteristics in the usage of online database: a representative nationwide survey of regional hospitals in Taiwan. Inform Health Soc Care 2009, 34:127-135.

34. Straus SE, Ball C, Balcombe N, Sheldon J, McAlister FA: Teaching evidencebased medicine skills can change practice in a community hospital. $J$ Gen Intern Med 2005, 20:340-343.

35. Glacken M, Chaney D: Perceived barriers and facilitators to implementing research findings in the Irish practice setting. J Clin Nurs 2004, 13:731-740.

36. Young JM, Ward JE: Evidence-based medicine in general practice: beliefs and barriers among Australian GPs. J Eval Clin Pract 2001, 7:201-210.

37. Shuval K, Shachak A, Linn S, Brezis M, Reis S: Evaluating primary care doctors' evidence-based medicine skills in a busy clinical setting. J Eval Clin Pract 2007, 13:576-580.

38. Hutchinson AM, Johnston L: Bridging the divide: a survey of nurses' opinions regarding barriers to, and facilitators of, research utilization in the practice setting. J Clin Nurs 2004, 13:304-315.

39. Toulkidis V, Donnelly NJ, Ward JE: Engaging Australian physicians in evidence-based medicine: a representative national survey. Intern Med J 2005, 35:9-17.

40. Retsas A: Barriers to using research evidence in nursing practice. J Adv Nurs 2000, 31:599-606.

doi:10.1186/1748-5908-8-112

Cite this article as: Weng et al:: Implementation of evidence-based practice across medical, nursing, pharmacological and allied healthcare professionals: a questionnaire survey in nationwide hospital settings. Implementation Science 2013 8:112.

\section{Submit your next manuscript to BioMed Central and take full advantage of:}

- Convenient online submission

- Thorough peer review

- No space constraints or color figure charges

- Immediate publication on acceptance

- Inclusion in PubMed, CAS, Scopus and Google Scholar

- Research which is freely available for redistribution 